\title{
The Role of Pulmonary Corticosteroid 11- Reductase Activity in Lung Maturation in the Fetal Rat
}

\author{
BARRY T. SMITH ${ }^{(30)}$
}

Department of Paediatrics, Queen's University, Kingston, Ontario, Canada

\section{Summary}

Injection of 11-ketoprogesterone into fetal rats at day 17 of gestation reduced the pulmonary $\mathrm{C}-11$ activation index (an indicator of net gain or loss of glucocorticoid activity) as measured at day $21(P<0.001)$ and resulted in elevated levels of the inactive hormone 11-dehydrocorticosterone $(P<0.001)$, but unchanged corticosterone levels. Adrenal weight was significantly increased $(P<0.001)$. 11-Ketoprogesterone-injected fetuses had considerably larger lungs $(P<0.001)$ with reduced saturated phosphatidylcholine content $(P<0.001)$.

\section{Speculation}

Prenatal glucocorticoid treatment to accelerate fetal lung maturation is an attempt to mimic a physiologic process. Further understanding of that process should provide means to enhance the safety and efficacy of such therapeutic intervention.

A large body of experimental evidence suggests that fetal lung maturation is under the influence of the fetal corticosteroid environment $(1,4,6,11,15,19-21)$. Corticosteroid biogenesis and metabolism are distinctly different in the fetal, as opposed to the adult, mammal (8). Among the important differences is the preponderance of biologically inactive 11-ketosteroids (cortisone (23), 11-dehydrocorticosterone) over active $11 \beta$-hydroxysteroids (cortisol, corticosterone) (12). This has been assumed to be due to a developmental inability of fetal tissues to "activate" 11 -keto- to $11 \beta$-hydroxysteroids $(13,14)$. Nevertheless, the fetal lung does possess the necessary enzymic activity (11-reductase) to convert abundant 11-ketosteroids to their active $11 \beta$-hydroxy-configurations $(7,16,17,21,22)$ and this activity increases with advancing gestational age $(16,22)$.

We have recently shown that, in both ovine (20) and human (19) amniotic fluid, the ratio of cortisol/cortisone is related to the state of fetal lung maturity, and this relationship is statistically more significant than that of cortisol alone, suggesting that the metabolic interrelationship of 11 -keto- and $11 \beta$-hydroxycorticosteroids plays a role in the process of fetal lung development.

The present study was initiated to determine whether this supposition might be correct, by observing the effect on pulmonary maturation in the fetal rat of injection of an inhibitor of pulmonary steroid 11-reductase activity (11-ketoprogesterone) (21).

\section{MATERIALS AND METHODS}

Female Sprague-Dawley rats were bred with a male brown hooded rat under accurately timed conditions in our laboratory. On the 17th day of gestation a laparotomy was performed under sterile conditions, using ether anesthesia. The gravid uterus was exposed and, through the translucent uterine wall, all fetuses in one horn were injected intraperitoneally with 0.2 $\mathrm{mg} 11$-ketoprogesterone $(24)$ in $0.3 \mathrm{ml}$ propylene glycol. The remaining fetuses in the second uterine horn were injected with $0.3 \mathrm{ml}$ propylene glycol alone. The uterine horn chosen for injection of 11-ketoprogesterone was alternated in successive animals. The abdominal incision was closed and the rats allowed to recover.

Four days later, on day 21 of gestation ( 1 day before the expected day of parturition), the mothers were killed by a blow to the head and the fetuses were removed for study. For each fetus, body weight, lung weight, and adrenal weight were determined.

For the determination of fetal pulmonary 11-oxidoreductase activity, one lung was taken from each fetus, homogenized, and incubated in Earle's balanced salt solution, $\mathrm{pH} 7.4$ (25) containing equimolar amounts $\left(8.3 \times 10^{-7} \mathrm{M}\right)$ of $\left[{ }^{14} \mathrm{C}\right]$ cortisone (New England Nuclear, lot no. $746-160$, sp act $59.8 \mathrm{mCi} / \mathrm{mmol}: 1.2$ $\times 10^{5} \mathrm{dpm}$ ) and $\left[{ }^{3} \mathrm{H}\right]$ cortisol (New England Nuclear, lot no. $853-263$, sp act $40 \mathrm{Ci} / \mathrm{mmol}: 1.1 \times 10^{6} \mathrm{dpm}$ ) at a concentration of $10 \mathrm{mg}$ tissue $/ \mathrm{ml}$. The incubation was carried out in a metabolic shaking incubator at $37^{\circ}$ for $2 \mathrm{hr}$ under $5 \% \mathrm{CO}_{2}$. After the incubation, cortisone and cortisol were extracted, separated chromatographically, and counted exactly as previously described (16). The percentage of conversion of cortisol to cortisone (11-oxidation $=$ biologic inactivation) was subtracted from the percentage of conversion of cortisone to cortisol $(11$-reduction $=$ biologic activation $)$ to give the " $\mathrm{C}-11$ activation index," an indicator of net gain (or loss) of biologic activity (16).

The remaining lung of each fetus was processed for the quantitation of saturated phosphatidylcholine. They were homogenized in $15 \mathrm{ml}$ chloroform-methanol $(2: 1)$. To each was added $3000 \mathrm{dpm}{ }^{14} \mathrm{C}$-saturated phosphatidylcholine, prepared in our laboratory as previously described (20). After refrigeration overnight at $5^{\circ} \mathrm{C}$, each sample was shaken with $5 \mathrm{ml}$ aqueous $100 \mathrm{mM} \mathrm{KCl} \mathrm{(5).} \mathrm{The} \mathrm{lower} \mathrm{(organic)} \mathrm{phase} \mathrm{was}$ removed, filtered, and evaporated to dryness. The lipid extracts were reacted with osmium tetroxide, $3.2 \mathrm{mg}$ in $0.5 \mathrm{ml}$ of carbon tetrachloride, for 15 min $(10,20)$. After drying, saturated phosphatidylcholine was isolated by column chromatography over neutral alumina $(10,20)$, and quantitated by the Bartlett phosphorus assay (2) with results corrected for experimental losses by the recovery of added ${ }^{14} \mathrm{C}$.

The fetal carcasses were homogenized in $30 \mathrm{ml}$ ethyl acetate and the homogenates were extracted three times with $10 \mathrm{ml}$ distilled water. After decolorization with $3 \mathrm{ml} 0.1 \mathrm{~N} \mathrm{NaOH}$ and washing to neutrality $(19,20)$, the ethyl acetate extracts were evaporated to dryness and applied to silica gel $G$ plates in a few drops of methylene chloride. The plates were developed in chloroform-methanol $(9: 1)$ and areas running with authentic corticosterone and 11-dehydrocorticosterone standards (24) were eluted with ethanol. Aliquots of the eluates were assayed for steroid content by radiotransinassay, using $\left[{ }^{3} \mathrm{H}\right]$ cortisol as ligand, exactly as previously described $(19,20)$. For corticosterone, $5 \%$ human plasma (26) was used as the source of corticos- 
teroid binding globulin, whereas, in the case of 11-dehydrocorticosterone, $5 \%$ dog plasma (obtained locally) was used. Results are reported as nanograms of steroid per $\mathrm{g}$ tissue.

In addition to the experimental litters, the above studies were also carried out on unoperated litters at daily intervals from day 17 to day 21 of gestation to provide normal values with which to compare our experimental observations.

All values are reported as means $\pm S D$. Differences between groups of observations have been compared using Student's $t$ test.

\section{RESULTS}

The surgical procedure was associated with considerable fetal mortality $(47 \%)$. This, however, could not be attributed to the 11-ketoprogesterone since the fetal loss was $37 \%$ in experimental fetuses and $56 \%$ in vehicle-injected controls. In addition, there is a normal background of fetal wastage in late gestation in multigravid species such as the rat, as reflected by a decrease in average litter size from 13 at days 17 and 18 to 8 at day 21 in our nonoperated control group (a reduction of $39 \%$ ).

Normal body, lung, and adrenal weights for fetal rats bred in our laboratory are shown in Table 1 . As shown, body weight and lung weight increase rapidly over the latter days of gestation, as compared to a more modest rate of increase of adrenal weight. The effect of 11-ketoprogesterone injection on these parameters is shown in Table 2 . It can be seen that body weight was not affected by 11-ketoprogesterone injection $(3.6 \pm 0.5$ $\mathrm{g})$ or by vehicle injection alone $(3.6 \pm 0.5 \mathrm{~g})$, since these values do not differ significantly from those of unoperated 21-day fetuses $(3.9 \pm 0.4 \mathrm{~g})$. In contrast, 11-ketoprogesterone injected fetuses had considerably larger lungs $(147.6 \pm 9.8 \mathrm{mg})$ than either vehicle-injected controls $(132.8 \pm 9.5 \mathrm{mg}, P<0.001)$ or normal 21 -day fetuses $(135.2 \pm 16.4, P<0.001)$. Similarly, adrenal weight was increased by 11 -ketoprogesterone injection $(P<0.001)$.

Normal levels of corticosterone, 11-dehydrocorticosterone, their ratio, and the C-11 activation index are shown in Table 3. Levels of both steroids increase with advancing gestational age, but corticosterone (the active hormone) rises more rapidly, resulting in a rising ratio. This appears to be due, at least in part, to the rapid increase in the pulmonary $\mathrm{C}-11$ activation index. The greatest increase in corticosterone levels and the corticosterone/11-dehydrocorticosterone ratio occurs between the 17 th and 18 th days, when the final stages of lung maturation are initiated. This is accompanied by a shift in the C-11 activation index from a negative value (net inactivation) on day 17 to a positive value (net activation) on day 18 . As shown in Table 4 , the C-11 activation index on day 21 is strikingly depressed by 11 -ketoprogesterone injection $(P<0.001)$. This is accompanied by a lowered corticosterone/11-dehydrocorticosterone ratio $(P<0.001)$, explainable by elevated levels of the inactive hormone 11-dehydrocorticosterone $(P<0.01)$, since corticosterone levels were unchanged.

In Table 5 is shown the normal increase in pulmonary saturated phosphatidylcholine content which reflects the biochemical maturation of the fetal lung. In Table 6 it can be seen that 11-ketoprogesterone injection reduced saturated phospha-

Table 1. Body and organ weights in fetal rats at various gestational ages $(G A)$ (means $\pm S D$ )

\begin{tabular}{ccccc}
\hline $\begin{array}{c}\text { GA, } \\
\text { days }\end{array}$ & $\begin{array}{c}\text { No. of fe- } \\
\text { tuses }^{1}\end{array}$ & Body wt, g & Lung wt, mg & $\begin{array}{c}\text { Adrenal wt, } \\
\text { mg }\end{array}$ \\
\hline 17 & $12(1)$ & $0.5 \pm 0.05$ & $10.0 \pm 4.1$ & \\
18 & $25(2)$ & $1.2 \pm 0.2$ & $40.4 \pm 9.2$ & $1.2 \pm 0.5$ \\
19 & $11(1)$ & $1.6 \pm 0.1$ & $52.6 \pm 7.1$ & $1.5 \pm 0.5$ \\
20 & $11(1)$ & $2.5 \pm 0.2$ & $98.0 \pm 14.3$ & $2.1 \pm 0.5$ \\
21 & $24(3)$ & $3.9 \pm 0.4$ & $135.2 \pm 16.4$ & $2.5 \pm 0.7$ \\
\hline
\end{tabular}

${ }^{1}$ Number of litters is shown in parentheses.
Table 2. Effect of 11-ketoprogesterone on body and organ weights at 21 days gestation (means $\pm S D$ )

\begin{tabular}{lcccc}
\hline \multicolumn{1}{c}{ Group } & $\begin{array}{c}\text { No. of } \\
\text { fetuses }^{1}\end{array}$ & Body wt, g & Lung wt, mg & $\begin{array}{c}\text { Adrenal wt, } \\
\mathrm{mg}\end{array}$ \\
\hline Experimental & $21(5)$ & $3.6 \pm 0.5$ & $147.6 \pm 9.8$ & $3.4 \pm 1.0$ \\
$\begin{array}{l}\text { Vehicle- } \\
\text { injected }\end{array}$ & $14(4)$ & $3.6 \pm 0.5$ & $132.8 \pm 9.5$ & $2.7 \pm 0.6$ \\
$\begin{array}{l}\text { Unoperated } \\
\text { Controls }\end{array}$ & $24(3)$ & $3.9 \pm 0.4$ & $135.2 \pm 16.4$ & $2.5 \pm 0.7$ \\
\hline
\end{tabular}

1 Number of litters is shown in parentheses.

Table 3. Steroid levels, corticosterone/11-dehydrocorticosterone ratios, and C-11 activation index at various gestational ages (GA) (means $\pm S D$ )

\begin{tabular}{ccccc}
\hline $\begin{array}{c}\text { GA, } \\
\text { days }\end{array}$ & $\begin{array}{c}\text { Corticoster- } \\
\text { one, } \mathrm{ng} / \mathrm{g}\end{array}$ & $\begin{array}{c}\text { 11-Dehydro- } \\
\text { corticosterone, } \\
\mathrm{ng} / \mathrm{g}\end{array}$ & Ratio $^{1}$ & $\begin{array}{c}\text { C-11 acti- } \\
\text { vation, \% }\end{array}$ \\
\hline 17 & $\mathbf{8 . 8 \pm 6 . 2}$ & $29.8 \pm 17.7$ & $0.28 \pm 0.05$ & $-5.7 \pm 2.6$ \\
18 & $33.8 \pm 12.1$ & $90.9 \pm 15.2$ & $0.36 \pm 0.09$ & $19.2 \pm 4.9$ \\
19 & $54.5 \pm 12.8$ & $122.4 \pm 18.4$ & $0.44 \pm 0.05$ & $30.6 \pm 6.1$ \\
20 & $58.2 \pm 14.6$ & $116.5 \pm 23.0$ & $0.50 \pm 0.03$ & $43.9 \pm 3.3$ \\
21 & $57.7 \pm 13.5$ & $112.8 \pm 24.8$ & $0.51 \pm 0.04$ & $47.7 \pm 4.3$ \\
\hline
\end{tabular}

${ }^{1}$ Corticosterone divided by 11 -dehydrocorticosterone.

Table 4. Effect of 11-ketoprogesterone on steroid levels, corticosterone/11-dehydrocorticosterone ratios, and C-11 activation index at 21 days of gestation (means $\pm S D$ )

\begin{tabular}{|c|c|c|c|c|}
\hline Group & $\begin{array}{c}\text { Corticos- } \\
\text { terone, } \\
\text { ng/g }\end{array}$ & $\begin{array}{l}\text { 11-Dehy- } \\
\text { drocorti- } \\
\text { costerone, } \\
\mathrm{ng} / \mathrm{g}\end{array}$ & Ratio $^{1}$ & $\begin{array}{l}\mathrm{C}-11 \text { acti- } \\
\text { vation, } \%\end{array}$ \\
\hline \multirow[t]{2}{*}{ Experimental } & 56.9 & 159.9 & 0.36 & 9.9 \\
\hline & \pm 12.6 & \pm 33.8 & \pm 0.05 & \pm 3.3 \\
\hline \multirow{2}{*}{$\begin{array}{l}\text { Vehicle- } \\
\text { injected }\end{array}$} & 55.5 & 114.0 & 0.49 & 51.7 \\
\hline & \pm 11.4 & \pm 21.5 & \pm 0.04 & \pm 6.1 \\
\hline Unoperated & 57.7 & 112.8 & 0.51 & 47.7 \\
\hline Controls & \pm 13.5 & \pm 24.8 & \pm 0.04 & \pm 4.3 \\
\hline
\end{tabular}

${ }^{1}$ Corticosterone divided by 11 -dehydrocorticosterone.

Table 5. Pulmonary saturated phosphatidylcholine (DSPC) at various gestational ages $(G A)$ (means $\pm S D$ )

\begin{tabular}{ccc}
\hline GA, days & DSPC, $\mathrm{mg} / \mathrm{g}$ lung & DSPC, mg/lung \\
\hline 17 & $0.81 \pm 0.10$ & $0.008 \pm 0.004$ \\
18 & $1.07 \pm 0.08$ & $0.043 \pm 0.010$ \\
19 & $1.29 \pm 0.11$ & $0.068 \pm 0.011$ \\
20 & $1.38 \pm 0.10$ & $0.136 \pm 0.024$ \\
21 & $1.66 \pm 0.11$ & $0.220 \pm 0.030$ \\
\hline
\end{tabular}

Table 6. Effect of 11-ketoprogesterone on pulmonary saturated phosphatidylcholine (DSPC) at 21 days of gestation (means \pm $S D)$

\begin{tabular}{lcc}
\hline Group & DSPC, mg/g lung & DSPC, mg/lung \\
\hline $\begin{array}{l}\text { Experimental } \\
\begin{array}{l}\text { Vehicle- } \\
\text { injected }\end{array}\end{array}$ & $1.42 \pm 0.09$ & $0.20 \pm 0.02$ \\
$\begin{array}{c}\text { Unoperated } \\
\text { controls }\end{array}$ & $1.77 \pm 0.11$ & $0.24 \pm 0.02$ \\
\hline
\end{tabular}


tidylcholine, whether considered as $\mathrm{mg} / \mathrm{g}$ lung weight $(P<$ 0.001 versus both vehicle injected and unoperated controls) or as milligrams per lung $(P<0.001$ versus vehicle-injected controls; $P<0.05$ versus unoperated controls). Saturated phosphatidylcholine was increased in vehicle-injected controls when compared to unoperated controls $(P<0.01)$, perhaps reflecting stress-induced acceleration of fetal lung maturation.

\section{DISCUSSION}

Injection of fetal rats with 11-ketoprogesterone at day 17 of gestation reduced the pulmonary conversion of the biologically inactive, but abundant, 11-ketosteroid, 11-dehydrocorticosterone, to its biologically active $11 \beta$-hydroxy form (corticosterone) and delayed lung maturation as reflected by reduced pulmonary saturated phosphatidylcholine content (the essential component of the pulmonary surfactant) (9). This would appear to support the concept, derived from indirect evidence $(19,20)$, that pulmonary 11-reductase activity facilitates the maturation of the fetal lung.

It is likely that the delayed lung maturation observed is, in fact, due to inhibition of the 11-reductase enzyme system, since, in vitro, this steroid has no effect on saturated phosphatidylcholine biosynthesis, nor does it reduce the effect of active (11 $\beta$-hydroxy) glucocorticoid on this process (21).

The delayed maturation was accompanied by increased lung weight. A similar observation was made when pulmonary maturation was delayed by fetal decapitation (4). Conversely, steroidinduced acceleration of fetal lung maturation is accompanied by reduced pulmonary cellular growth both in vivo (3) and in vitro (18).

Despite significant reduction of pulmonary 11 -reductase activity by 11-ketoprogesterone, as measured directly and as reflected by elevation of precursor (11-dehydrocorticosterone) levels, corticosterone levels remained unchanged. This was accompanied, however, by increased fetal adrenal weight. This may imply that, under normal conditions, fetal pulmonary 11reductase makes a significant contribution to circulating active $11 \beta$-hydroxy steroids, but reduction of this contribution can be compensated for by increased fetal pituitary-adrenal activity. The fact that fetal lung maturation was delayed despite normal corticosterone levels suggests that the favorable effect of pulmonary 11-reductase activity on lung maturation depends in part upon maintenance of relatively higher levels of active hormone within the lung parenchyma.

Alternatively, it is possible that the elevated 11-dehydrocorticosterone levels reflect conversion of the injected 11-ketoprogesterone to this steroid by fetal adrenal 21-hydroxylase activity. Although the present data do not rule out this possibility, such a mechanism would not explain either the increased fetal adrenal weight or the reduced pulmonary saturated phosphatidylcholine.

\section{REFERENCES AND NOTES}

1. Ballard, P. L., and Ballard, R. A.: Cytoplasmic receptor for glucocorticoids in lung of the human fetus and neonate. J. Clin. Invest., 53: 477 (1974)
2. Bartlett, G. R.: Phosphorus assay in column chromatography. J. Biol. Chem., 234: 466 (1959).

3. Carson, S. H., Taeusch, H. W., and Avery, M. E.: Inhibition of lung cell division after hydrocortisone injection into fetal rabbits. J. Appl. Physiol. 34: 660 (1973).

4. Farrell, P. M., and Blackburn, W. R.: Cortisol and lung choline phosphotransferase in the fetal rat after in utero decapitation. Pediat. Res., 7: 308 (1973)

5. Folch, J., Lees, M., and Sloane-Stanley, G. H.: A simple method for the isolation and purification of total lipids from animal tissues. J. Biol. Chem., 226: 497 (1957).

6. Giannopoulos, G.: Variations in the levels of cytoplasmic glucocorticoid receptors in lungs of various species at different developmental stages. Endocrinology, 94: 450 (1974).

7. Giannopoulos, G.: Uptake and metabolism of cortisone and cortisol by the fetal rabbit lung. Steroids, 23: 845 (1974).

8. Giroud, C. J. P.: Aspects of corticosteroid biogenesis and metabolism during the perinatal period. Clin. Obstet. Gynecol., 14: 745 (1971).

9. Goerke, J.: Lung surfactant. Biochim. Biophys. Acta, 344: 241 (1974).

10. Mason, R., Nellenbogen, J., and Clements, J. A.: Isolation of disaturated phoshatidylcholine with osmium tetroxide. J. Lipid Res., 17: 281 (1976). .

1. Murphy, B. E. P.: Evidence of cortisol deficiency at birth in infants with respiratory distress syndrome. J. Clin. Endocrinol. Metab., 38: 158 (1974). Cortisol and cortisone. J. Clin. Endocrinol. Metab., 35: 678 (1972).

13. Pasqualini, J. R., Costa Novaes, S., Ito, Y., and Nguyen, B. L.: Reciprocal cortisol-cortisone conversions in the total tissue and subcellular fractions of foetal and adult guinea pig liver. J. Steroid Biochem., 1: 341 (1970).

14. Pasqualini, J. R., Nguyen, B. L., Uhrich, F., Wiqvist, N., and Diczfalusy, E.: Cortisol and cortisone metabolism in the human foeto-placental unit at midgestation. J. Steroid Biochem., 1: 209 (1970).

15. Sharp-Cageorge, S. M., Blicher, B. M., Gordon, E. R., and Murphy, B. E. P.: Amniotic fluid cortisol and human fetal lung maturation. New Engl. J. Med., 296: 89 (1977).

16. Smith, B. T., and Giroud, C. J. P.: Effects of cortisol on serially propagated fibroblast cell cultures derived from the rabbit fetal lung and skin. Can. J. Physiol. Pharmacol., 53: 1037 (1975).

17. Smith, B. T., Torday, J. S., and Giroud, C. J. P.: The growth promoting effect of cortisol on human fetal lung cells. Steroids, 22: 515 (1973).

18. Smith, B. T., Torday, J. S., and Giroud, C. J. P.: Evidence for different gestation-dependent effects of cortisol on cultured fetal lung cells. J. Clin. Invest., 53: 1518 (1974).

19. Smith, B. T., Worthington, D., and Maloney, A. H. A.: The amniotic fluid cortisol/cortisone ratio in pre-term human delivery. Obstet. Gynecol. 49: 527 (1977).

20. Smith, B. T., Worthington, D., and Piercy, W. N.: The relationship of cortisol and cortisone to saturated lecithin concentration in ovine amniotic fluid and fetal lung liquid. Endocrinology, 101: 104 (1977).

21. The rabbit fetal lung as a glucocorticoid target tissue. Endocrinology, 96: 1462 (1975).

22. Torday, J. S., Olson, E. B., and First, N. L.: Producion of cortisol from cortisone by the isolated, perfused fetal rabbit lung. Steroids, 27: 869 (1976).

23. The abreviations used are cortisol: $11 \beta, 17 \alpha, 21$-trihydroxy pregn-4-ene-3, 20-dione; cortisone: $17 \alpha, 21$-dihydroxypregn-4-ene-3,11,20-trione; corticosterone: $11 \beta, 21$-dihydroxypregn-4-ene-3,20-dione; 11-dehydrocortico21-hydroxypregn-4-ene-3, 11, 20-trione sterone; 11-ketoprogester-: pregn4-ene-3,11,20-trione.

24. Steraloids, Inc., Pawling, N. Y.

25. Gibco Canada Ltd., Burlington, Ontario.

26. Versatol-A, Warner Lambert, Montreal.

27. I thank D. Minshal, J. Sahasra-Budhe, and E. Vreeken for expert technical assistance.

28. This research was supported by the Medical Research Council of Canada.

29. Dr. B. T. Smith is Scholar, Medical Research Council of Canada.

30. Requests for reprints should be addressed to: B. T. Smith, M.D., Departmen of Paediatrics, Queen's University, Kingston, Ontario, K71 3N6 (Canada).

31. Received for publication March 4, 1977.

32. Accepted for publication April 26, 1977. 